\title{
REVIEW
}

\section{Molecular mechanisms of FOX01 in adipocyte differentiation}

\author{
Junye Chen 1,2, Yi Lu'3,4, Mengyuan Tian ${ }^{1,2}$ and Qiren Huang 3,4 \\ 1Jiangxi Medical College, Nanchang University, Nanchang, Jiangxi Province, People's Republic of China \\ 2Nanchang Joint Programme, Queen Mary, University of London, London, UK \\ ${ }^{3}$ Key Provincial Laboratory of Basic Pharmacology, Nanchang University, Nanchang, Jiangxi Province, People's Republic of China \\ 4Department of Pharmacology, School of Pharmacy, Nanchang University, Nanchang, Jiangxi Province, People's Republic of China
}

Correspondence should be addressed to Q Huang: qrhuang@ncu.edu.cn

\begin{abstract}
Forkhead box-O1 (FOXO1) is a downstream target of AKT and plays crucial roles in cell cycle control, apoptosis, metabolism and adipocyte differentiation. It is thought that FOXO1 affects adipocyte differentiation by regulating lipogenesis and cell cycle. With the deepening in the understanding of this field, it is currently believed that FOXO1 translocation between nuclei and cytoplasm is involved in the regulation of FOXO1 activity, thus affecting adipocyte differentiation. Translocation of FOXO1 depends on its post-translational modifications and interactions with 14-3-3. Based on these modifications and interactions, FOXO1 could regulate lipogenesis through PPAR $\gamma$ and the adipocyte cell cycle through p21 and p27. In this review, we aim to provide a comprehensive FOXO1 regulation network in adipocyte differentiation by linking together distinct functions mentioned above to explain their effects on adipocyte differentiation and to emphasize the regulatory role of FOX01. In addition, we also focus on the novel findings such as the use of miRNAs in FOXO1 regulation and highlight the improvable issues, such as RNA modifications, for future research in the field.

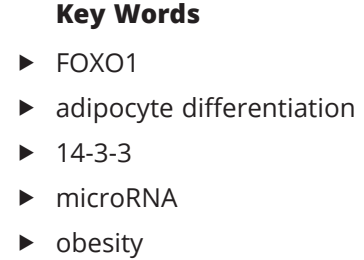

Journal of Molecular Endocrinology (2019) 62, R239-R253
\end{abstract}

\section{Introduction}

Obesity is considered to be a syndrome involving chronic and low-level inflammatory response characterized by abnormal production of cytokines and activation of the inflammatory response signalling pathway in adipose tissues (Hotamisligil 2006). Obesity normally means adipocyte hypertrophy and/or hyperplasia, as well as an imbalance between the deposition and expenditure of energy ( $\mathrm{Wu}$ et al. 2017). Adipokines secreted from adipocytes can cause several kinds of obesity-related complications. Indeed, adipose tissue can be divided into white adipose tissue (WAT) and brown adipose tissue (BAT). WAT is the most predominant adipose tissue extensively located at the subcutaneous compartment (referred to as subcutaneous WAT) and the surrounding of internal organs (also known as visceral WAT) (Cinti 2005). WAT is responsible for storage of excess energy in the form of triglycerides and production of adipokines, which readily leads to obesity, inflammation and cancers (Cinti 2005, Qiang et al. 2012). Whereas, BAT combusts fat by dissipating heat mediated by uncoupling protein 1 (UCP-1) in mitochondria (Cinti 2005). In 2012, Boström et al. found the existence of a third adipocyte type, named brown-fat-like (Boström et al. 2012). Currently, scientists term it 'beige' or 'brite' adipocytes, which are generally considered as a middle state between the white and brown adipocytes (Wu et al. 2012, Harms \& Seale 2013). 
The transcription factor FOXO family comprises FOXO1, FOXO3, FOXO4 and FOXO6 (Ogg et al. 1997, Tzivion et al. 2011). FOXO1 is one of the downstream targets of AKT (Fig. 1) and takes part in cell cycle control, apoptosis, metabolism and adipocyte differentiation (Dowell et al. 2003, Battiprolu et al. 2012, Song et al. 2015). FOXO1 is normally expressed in insulin-responsive tissues and organs (Nakae et al. 2002, 2003, Dowell et al. 2003), such as the liver, adipose tissue and pancreas. It contains three highly conserved phosphorylation sites in mice, T24, S253 and S316 (corresponding phosphorylation sites in humans are T24, S256 and S319; Asada et al. 2007) targeted by phosphorylated AKT (Fig. 1) (Nakae et al. 1999). The phosphorylation of FOXO1 at these sites by AKT inhibits the transcriptional activation mediated by FOXO1. Similarly, the acetylation of FOXO1 attenuates its DNA-binding affinity and promotes its shuttling from nuclei to cytoplasm (Yang $\&$ Seto 2008). Accordingly, its acetylation could enhance the effect of AKT phosphorylation to further inhibit the transcriptional activation by FOXO1 (Calnan \& Brunet 2008). FOXO1 is widely studied in cancer due to its regulation of the cell cycle (Nakae et al. 2002, 2008a, Song et al. 2015). Given this condition, it is well thought that FOXO1 is involved in the regulation of the cell cycle during adipocyte differentiation (Nakae et al. 2002, 2003, 2008a). Numerous studies have shown that PPAR $\gamma$ is a prerequisite for adipocyte differentiation and activated FOXO1 could inhibit lipogenesis via PPAR (Evans et al. 2004, Dominy \& Puigserver 2010, Song et al. 2010, Qiang et al. 2012). Based on the accumulated knowledge in this field and our previous studies (Wu et al. 2017, Lu et al. 2018), this review summarizes the mechanism of FOXO1 in the regulation of adipocyte differentiation in order to shed light on the potential further research.

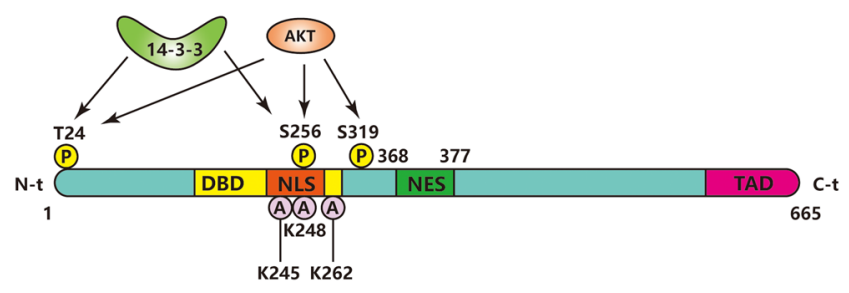

Figure 1

Schematic of human FOXO1 primary structure. FOXO1 contains the forkhead DBD, NLS, NES and TAD domains. Acetylation sites (K245, K248 and K262) by CBP/P300, phosphorylation sites (T24, S256 and S319) by AKT and 14-3-3 binding sites (T24 and S256) are shown. DBD, DNAbinding domain; NES, nuclear export sequence; NLS, nuclear localization signal; TAD, transactivation domain. A full colour version of this figure is available at https://doi.org/10.1530/JME-18-0178.

(c) 2019 Society for Endocrinology Published by Bioscientifica Ltd. Printed in Great Britain

\section{Research history of FOX01}

Researches on FOXO1 has been going on for more than two decades. In 1993, FOXO1 gene was cloned for the first time by Galili et al. in the study of the $t(2 ; 13)$ chromosomal translocation in rhabdomyosarcoma (Galili et al. 1993). It was found that a gene encoding the transcription factor paired box 3 (PAX3) fused with another gene encoding a homology protein containing the forkhead DNA-binding domain (DBD). X-ray crystallography (Clark et al. 1993) and nuclear magnetic resonance analyses (Jin et al. 1998) then showed that FOXO1 has a butterfly-like structure. Moreover, Clark et al. further characterized the threedimensional structure of the DBD of HNF-3 $\gamma /$ forkhead complexed with DNA at $2.5 \AA$ resolution (Clark et al. 1993). The secondary structure of the forkhead domain contains four $\alpha$-helices (H1, H2, H4 and H3), three $\beta$-strands (S1-S3) and two winged loops (W1 and W2) (Jin et al. 1998, Obsil \& Obsilova 2011). H1 and H2 present H3 to the major groove of double-stranded DNA, where H3 directly interacts with the target DNA sequence (Clark et al. 1993, Obsil \& Obsilova 2011). The dynamic data strongly supported the presence of $\mathrm{H} 4$ (Marsden et al. 1997) and the fourth helix was further proved to be inserted between $\mathrm{H} 2$ and H3 (Marsden et al. 1998). These findings fuelled further studies on FOXO1.

In 1996, Kohn et al. reported that overexpression of constitutively activated AKT could promote adipocyte differentiation (Kohn et al. 1996). Thereafter, Sakaue et al. found that adipocyte differentiation is related to PI3K (Sakaue et al. 1998). Until 1999, Datta et al. found that AKT could inhibit the transcriptional activity of FOXOs (Datta et al. 1999). A reduction in the transcriptional activity of FOXO1 caused by AKT phosphorylation was detected (Kaestner et al. 2000). In 2001, Nakae et al. confirmed that FOXO1 was involved in the regulation of G6P and PEPCK (Nakae et al. 2001). In 2003, Hribal et al. found that FOXO1 was regulated by PI3K in myoblast differentiation (Hribal et al. 2003). Meanwhile, Nakae et al. also found that FOXO1 was regulated by PI3K in adipocytes (Nakae et al. 2003). They reported that haploinsufficient Foxo1 ${ }^{+/-}$could restore the number and size of adipocytes in mice fed with high-fat diet (Nakae et al. 2003). Moreover, constitutively active non-phosphorylated nuclear FOXO1 inhibited the differentiation of preadipocytes (Nakae et al. 2003). Dominant-negative Foxo1 with deletion of transcriptional activation domain (TAD) restored the differentiation of embryonic fibroblasts isolated from insulin receptor knockout mice and promoted adipocyte differentiation in vitro (Nakae et al. 2008a). Knockdown of Foxo1 was 
found to significantly suppress adipocyte differentiation as well (Munekata \& Sakamoto 2009). Moreover, Nakae et al. further found that FCoR, a murine FOXO1 inhibitor, could directly acetylate FOXO1 through its intrinsic acetyltransferase activity. It can also disturb the interaction between SIRT1 and FOXO1 to inhibit the deacetylation of FOXO1 since SIRT1 is a deacetylase for FOXO1. Based on these two mechanisms, FCoR could curtail FOXO1 activity and promote adipocyte differentiation (Nakae et al. 2012). Of note, Fcor has no human analogue, which requires further researches for humans. Matsumoto et al. confirmed that FOXO1 is required for the function of PGC1 that promotes translation of Ucp1 during brown adipocyte differentiation (Matsumoto et al. 2007). Ortega-Molina et al. reported that BAT has lower levels of phosphorylated AKT and phosphorylated FOXO1 as well. Then they verified that Ptentg, carrying additional copies of Pten, could induce the binding of FOXO1 to the promoters of $U c p 1$ and $P g c 1$, thus ameliorating brown adipocyte differentiation (Ortega-Molina et al. 2012). Recently, Nagashima et al. identified numerous compounds bound to purified FOXO1 by mass spectrometry affinity screening. One of them is 5-amino-7-cyclohexylaminoacyl-1-ethyl-6-fluoro-4-oxo-1-dihydroquinoline-3carboxylic acid (AS1842856) (Nagashima et al. 2010). It has been shown that AS1842856 is a FOXO1 inhibitor that inhibits the transcriptional activity of FOXO1 by blocking the phosphorylation of FOXO1 and repressing interaction with DNA-binding sites (Zou et al. 2014). By means of such a mechanism, AS1842856 can further restrain autophagy, lipid accumulation (Liu et al. 2016) and adipocyte differentiation (Zou et al. 2014). At present, a large number of studies on FOXO1 in adipocyte differentiation are still continuing.

\section{Dynamics of FOX01 activation during adipocyte differentiation}

Based on in vitro studies, the process of adipocyte differentiation contains several stages, including multipotent mesenchymal precursors, committed preadipocytes, growth arrest, mitotic clonal expansion, terminal differentiation and maturation of adipocytes (Tang et al. 2003, Gerin et al. 2009). When the preadipocyte cells grow to the $90 \%$ confluence, the growth inhibition resultantly occurs. At the clonal expansion stage, cells re-enter the cell cycle and carry out mitosis at least two times under the stimulation of lipogenic hormones and mitogenic compounds (Cornelius et al. 1994, Shamina \& Rangwala 2000). During the terminal differentiation stage, cells return to the growth arrest stage and result in the transformation from immature adipocytes to mature adipocytes (Cornelius et al. 1994, Shamina \& Rangwala 2000). Zou et al. studied the activation and inactivation kinetics of FOXO1 through the phosphorylation and dephosphorylation of FOXO1 during adipocyte differentiation under natural conditions. The findings indicated that FOXO1 presented a sigmoid activation pattern during adipocyte differentiation (Zou et al. 2014). FOXO1 in 3T3-L1 preadipocytes was the least active on day 1 presented as inactivation peak 1 (IP1), which represented that cells re-entered the cell cycle and clonal expansion. Subsequently, FOXO1 reached the first activation peak (AP1) on day 3 when the cells were right in the growth arrest period after mitosis, which potently supports the fact that FOXO1 regulates the cell cycle of preadipocytes (Nakae et al. 2003, Cheng \& White 2011). IP2 occurred on day 5 accompanied by the expression upregulation of PPAR $\gamma$ and adiponectin, which was consistent with the results of Liu et al. (2014). IP3 appeared on day 9 between AP2 on day 7 and AP3 on day 10 (Zou et al. 2014). The 'terminal differentiation' phase (day 4-12) exhibits multiple switches of the activation-inactivation, implying that FOXO1 has a complex regulatory role. Since the activation of FOXO1 during adipocyte differentiation is a periodic dynamic fluctuation, this may explain the paradox occurred in some experiments. For example, Kim et al. reported an increase of p-FOXO1 and p-AKT in 3T3-L1 cells under the treatment with PI3K inhibitor analogues, such as epigallocatechin-3-gallate (EGCG) (Kim et al. 2010, Kim \& Sakamoto 2012).

\section{F0X01 shuttling between nucleus and cytoplasm}

FOXO1 normally stays in the nucleus and keeps its transcriptional activity, thereby it could serve as a downstream protein to control the cell cycle. Residues within the basic region of the FOXO1 DBD (Fig. 1) are essential for nuclear targeting (Rena et al. 2001). The shuttling of FOXO1 needs the interaction between importinsandexportins(VanDerHeideetal.2004).Exportin 1 , also termed as chromosomal region maintenance 1 protein (CRM1), recognizes nuclear export signals (NESs) presented in FOXO1 including leptomycin-sensitive NES (Vogt et al. 2005). NES contains a leucine-rich sequence downstream of the C-terminal AKT phosphorylation site, for instance, sequence MENLLDNLNLL of FOXO1 (Obsil \& Obsilova 2008). Nuclear localization signals (NLSs) do not correspond to a particular consensus sequence but instead 
form two different classes. One is called monopartite NLS, consisting of a single basic cluster of amino acid residues, and bipartite NLS comprising two basic clusters (Obsil \& Obsilova 2008). Pan et al. reported that FOXO1NESm (mutated) and FOXO1-NLSm primarily remained in the nucleus and the cytoplasm, respectively (Pan et al. 2017). In general, both NLS and NES interact with posttranslational modifications of FOXO1 to regulate the translocation of FOXO1. However, there have been only a few studies on NLS and NES of FOXO1, and the mechanism of their interactions still needs further exploration.

\section{F0X01 phosphorylation}

PI3K is a heterodimer comprising a catalytic subunit $(110 \mathrm{kDa})$ and a regulatory or adaptor subunit (Vanhaesebroeck \& Waterfield 1999, Vanhaesebroeck \& Alessi 2000). One of the main downstream mediators of PI3K signal is AKT, also known as PKB. The activated AKT is separated from plasma membrane and transported to cytoplasm and nucleus where it phosphorylates serine or threonine residues within AKT phosphorylation motifs of target proteins (Lawlor \& Alessi 2001).

The transcriptional activation of FOXO1 is mainly mediated by binding to the conservative recognition motif TTGTTTAC of target genes, and its activity is inhibited by insulin and insulin-like growth factor-1 (IGF-1) signalling pathways (Li et al. 2017). FOXO1 binds to the DNA target in nuclei via sequence-specific interactions mediated by $\mathrm{H} 3$ and basic regions in the C-terminal of DBD (Obsil \& Obsilova 2011). The interaction is expeditious and reversible, reflecting a dynamic process. Phosphorylation of FOXO1 at $\mathrm{S} 256$ by AKT decreases the binding affinity of FOXO1 to target DNA and increases the phosphorylation of other sites, such as T24 and S319 by AKT and other kinases, including serum- and glucocorticoid-induced kinase (SGK). The activity of FOXO proteins can be regulated by their cellular localization. Phosphorylation of FOXO1 causes it to be excluded from the nucleus (Zhang et al. 2002). Protein phosphatase 2 (PP2A) has been shown to be a FOXO1 phosphatase, which dephosphorylates FOXO1 either in the cytoplasm or in the nucleus (Yan et al. 2008).

Lu et al. demonstrated that EGCG or PI3K inhibitor LY294002 could repress the levels of p-FOXO1 and PI3K in 3T3-L1 cells and inhibit the adipocyte differentiation (Lu et al. 2018). Tang et al. found that the phosphorylation of all three AKT sites, or some of them, reduced the transcriptional activity of FOXO1 (Tang et al. 1999). They first demonstrated the mutations of three phosphorylation sites into alanine residues enhanced the transcriptional activity of FOXO1 and made it resistant to the inhibition by AKT. S256 is located in a basic region of the FOXO1 DBD (Fig. 1), and phosphorylation at S256 may directly affect FOXO1-DNA binding and nuclear targeting. Thus, Guo et al. found that insulin and insulin-like growth factors could induce S256 phosphorylation of FOXO1 and further inhibit its transactivation (Guo et al. 1999). The mutation of serine to alanine (S256A) in the forkhead domain of FOXO1 could completely abolish the increase in total FOXO1 phosphorylation induced by insulin, but mutations of N-terminal and C-terminal phosphorylation sites did not display such an effect (Nakae et al. 2000). Rena et al. found that the S256A FOXO1 mutant was a dominant-negative inhibitor of AKT, which prevented conformational changes due to phosphorylation and inhibited phosphorylation of T24 and S319 in vitro. At the same time, T24A and S319A mutations prevented them from being phosphorylated, but they did not inhibit phosphorylation at other sites (Rena et al. 2001). Therefore, the so-called 'gatekeeper' S256 phosphorylation is a prerequisite for phosphorylation of T24 and S319.

Phosphorylation of S256 is also involved in the process of nuclear exclusion. Phosphorylated FOXO1 enters the cytoplasm via nuclear exclusion and loses its transcriptional activity (Brunet et al. 1999). A transient transfection study showed that S256 phosphorylation could inhibit the function of FOXO1 independently and proved its prerequisite position to other phosphorylation (Rena et al. 2001). However, a GFP fusion protein assay showed that T24/S319 phosphorylation was a prerequisite for FOXO1 nuclear exclusion (Zhang et al. 2002). Heide et al. reported that phosphorylation of serine residues in AKT phosphorylation motifs of the FOXO1 forkhead domain introduces a negative charge, which may affect NLS (Van Der Heide et al. 2004). By replacing S256 with aspartate (S256D) and introducing negative charge at this site, the nuclear exclusion of FOXO1 can be induced, which is similar to phosphorylation at S256. Notably, the T24A and S319A mutants could lead to the nucleartargeting effect of FOXO1 and abrogate the effect of S256D on FOXO1 transport, thus abolishing nuclear exclusion (Zhang et al. 2002). Apparently, further research is needed to elucidate the relationship between these three residues.

Murine FOXO1 contains three highly conserved AKT recognition motifs, RXRXXS/T, in which ' $\mathrm{X}$ ' denotes any residue (Alessi et al. 1996). The AKT phosphorylation sites located in both the $\mathrm{N}$-terminus and the forkhead domain 
are responsible for the nuclear exclusion because they affect the function of NLS and the association with 14-3-3 proteins (Brunet et al. 1999, Brownawell et al. 2001). The human S256 AKT conservative phosphorylation motif on target protein is Arg-Arg-Arg-Ala-Ala-Ser, while FOXO1's residues 251-253 are exactly Arg-Arg-Arg, which conforms to this motif. Furthermore, since residues 251253 and 256 are also located within the DBD of FOXO1, the nuclear targeting of FOXO1 was completely abolished in unstimulated cells when these three arginine residues were replaced by neutral amino acids (Rena et al. 2001). Therefore, the three arginine residues are thought to be related to nuclear targeting. Altogether, phosphorylation of FOXO1 by AKT regulates the nuclear exclusion and nuclear targeting of FOXO1, thus affecting the transcriptional activity mediated by FOXO1.

\section{FOXO1 and 14-3-3}

The molecular weight of the $14-3-3$ is approximately $30 \mathrm{kDa}$. It has a U-shaped structure. With the 'U-structure', 14-3-3 can recognize and bind phosphorylated serine or threonine residues. Meanwhile, this protein can form homodimers and heterodimers with other family members (Van Der Heide et al. 2004). Scientists have shown that phosphorylated FOXO1 (p-FOXO1) can bind to 14-3-3 and become inactivated, which is caused by FOXO1 translocation (Fig. 2) (Brunet et al. 1999, 2002, Zhao et al. 2004, Tzivion et al. 2011).

\section{Binding of 14-3-3 to p-FOX01 promotes nuclear exclusion}

Nagashima et al. identified that purified FOXO1 bound to 14-3-3 by mass spectrometry (Nagashima etal. 2010). Brunet et al. further confirmed that after FOXO3 phosphorylation by AKT, 14-3-3 enhances the nuclear exclusion of FOXO3 by interacting with two nuclear export sequences located at the C-terminal of FOXO3. Moreover, 14-3-3 inhibits the re-entry of FOXO3 into nuclei by masking two NLSs, ${ }_{248} \mathrm{RRR}_{250}$ and ${ }_{269} \mathrm{KKK}_{271}$, which neighbour the binding sites of 14-3-3 and human FOXO3 phosphorylation site S253. Thus, the sequestration of FOXO3 in cytoplasm is promoted (Brunet et al. 2002). They also demonstrated that the bindings of 14-3-3 to phosphorylated FOXO1 in nuclei induces a conformational change of FOXO1, which exposes NES to exportin/CRM1 and promotes nuclear exclusion of the 14-3-3/FOXO1 complex (Brunet et al. 2002). Although the N-terminal-binding motif of 14-3-3 is far from NES, 14-3-3 can still affect the conformational

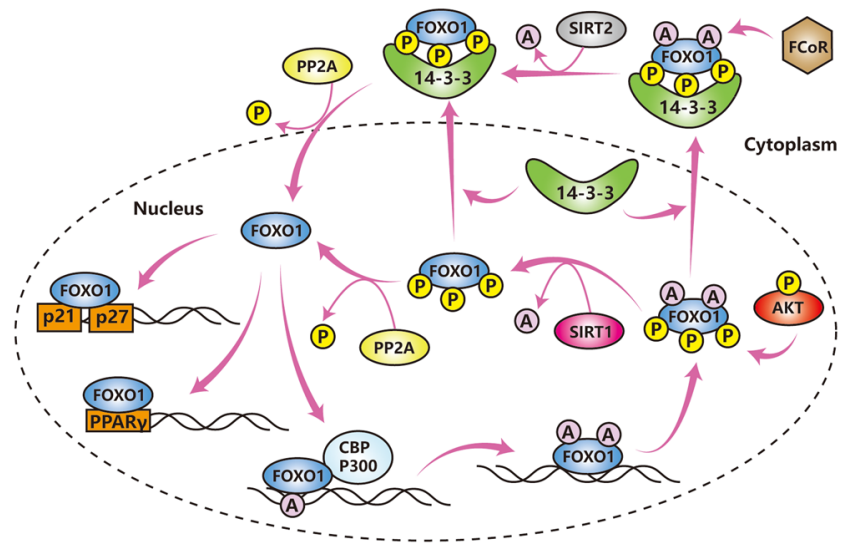

Figure 2

Schematic model for the regulation of FOXO1 by reversible phosphorylation and acetylation. FOXO1 recruits CBP/P300 to initiate an acetylation. After acetylation of FOXO1, the FOXO1 phosphorylation by p-AKT is induced, and then 14-3-3 binds to the phosphorylated sites to trigger the nuclear exclusion. SIRT1 and SIRT2 deacetylated FOXO1 in the nucleus and cytoplasm, respectively. PP2A dephosphorylates and activates FOXO1. Activated FOXO1 binds to the promoters of target genes encoding p21, p27 and PPAR $\gamma$ and initiates subsequent transcriptions. A full colour version of this figure is available at https://doi.org/10.1530/ JME-18-0178.

change. Therefore, 14-3-3 may control the subcellular localization of FOXO1 and simultaneously affect the function of FOXO1.

\section{Binding of 14-3-3 to p-FOXO1 inhibits the re-entry into nuclei}

AKT-mediated FOXO1 phosphorylation induces the binding of 14-3-3, and the resulting complex is easily transported to the cytoplasm. The complex of 14-3-3/ FOXO1 could prevent FOXO1 from re-entering nuclei by interfering with the NLS function of FOXO1 (Brownawell et al. 2001, Zhao et al. 2004, Obsilova et al. 2005, Silhan et al. 2009). Because the interaction between FOXO1 and 14-3-3 is dependent on the FOXO1 phosphorylation, blocking its phosphorylation in 'gatekeeper' S256 can abolish 14-3-3 binding and destroy the binding site of 14-3-3 (Yaffe 2002, Van Der Heide et al. 2004, Tzivion et al. 2011). Obsilova et al. studied the crystal structure of FOXO4 and verified the effect of 14-3-3 on the conformational change of FOXO NLS using a FOXO4 NLS model (Obsilova et al. 2005). Paradoxically, it was found that the binding of 14-3-3 to FOXO4 did not result in any dramatic conformational change. The results also displayed that the FOXO4 forkhead domain was anchored in the central channel of the 14-3-3 dimer, which is consistent with the assumption that 14-3-3 masks DNA 
binding. The non-classical bipartite NLS of FOXO1 contains 12 arginine and lysine residues located on both sides of the second AKT/14-3-3 binding motif in the forkhead domain. The two basic clusters are independent and normally both of them are required for nuclear targeting (Obsil \& Obsilova 2008). Therefore, 14-3-3 is considered to prevent nuclear reimport of FOXO1 by masking NLS (Brunet et al. 2002, Silhan et al. 2009).

\section{Binding of 14-3-3 to p-FOX01 prevents dephosphorylation and degradation}

Brunet et al. reported that AKT phosphorylation motifs of the N-terminal and forkhead domains in FOXO1 were involved in 14-3-3 binding (Brunet et al. 1999). Dobson et al. also indicated that the 14-3-3 binding stabilizes FOXO3 by suppressing its dephosphorylation and degradation, as well as the well-defined negative FOXO regulation (Dobson et al. 2011). Binding of 14-3-3 involves recognition of the RSXPSXP and RXXXpSXP motifs, where $\mathrm{pS}$ represents the phosphorylated serine residue (Hermeking \& Benzinger 2006). Therefore, FOXO1 has an ideal 14-3-3 binding site that overlaps the N-terminal AKT phosphorylation motif (Figs 1 and 2). Accordingly, 14-3-3 could prevent FOXO1 from dephosphorylation. Thus, the availability of 14-3-3 determines the fate of degradation or recycling of phosphorylated FOXO1. In general, by associating with NLS and NES of FOXO1, 14-3-3 achieves translocation between nucleus and cytoplasm. In the meantime, because of the overlap of AKT/14-3-3 binding motifs, 14-3-3 could reinforce the masking of NLS after phosphorylation to stabilize the status of FOXO1.

\section{F0X01 acetylation}

FOXO1 can be acetylated by CREB-binding protein (CBP/ P300) and P300/CBP-associated factor (P/CAF), while histone deacetylases (HDACs), such as SIRT1 and SIRT2, can deacetylate it (Fig. 2) (Xie et al. 2012). The acetylation of K222, K245, K248, K262, K265, K274 and K294 sites of FOXO1 has been reported to regulate its DNA-binding affinity and its sensitivity to AKT phosphorylation (Matsuzaki et al. 2005, Qiang et al. 2010). Among these sites, K245 and K248 are extremely particular because their acetylation substantially weakens the DNA-binding ability of FOXO1. In addition, the acetylation of K242, K245 and K262 are sufficient to reduce the transcriptional activity of FOXO1 (Wang et al. 2014). These three acetylation sites of FOXO1 (K242, K245 and K262) located in the W2 region of the forkhead domain are directly involved in DNA recognition and/or FOXO-DNA complex stabilization (Lai et al. 1993). It has been reported that acetylation of positively charged lysine residues in W2 region may inhibit the binding of FOXO to DNA (Matsuzaki et al. 2005). Accordingly, Brent et al. showed that the $\mathrm{W} 2$ region in the C-terminal of the forkhead domain was necessary for DNA binding, and FOXO1 acetylation mediated by CBP/ P300 reduced the DNA-binding affinity (Brent et al. 2008). By using acetylation-defective (3K-to-3R) and acetylationmimicking (3K-to-3A and 3K-to-3Q) mutants, Matsuzaki et al. confirmed that the acetylation of FOXO1 did reduce the affinity of DNA binding (Matsuzaki et al. 2005). To date, it has been identified that the acetylation of FOXO1 regulates its activity through three different mechanisms: (1) acetylation of lysine residues in the forkhead domain of FOXO1 reduces its binding ability to DNA; (2) FOXO1 acetylation promotes the phosphorylation of S256 of human FOXO1 mediated by AKT, which leads to nuclear exclusion; (3) FOXO1 acetylation can lead to nuclear exclusion independent of its phosphorylation state. On the contrary, FOXO1 deacetylation promotes nuclear retention (Matsuzaki et al. 2005, Qiang et al. 2010). Besides, Sewastianik et al. confirmed FOXO1 acetylation facilitated its proapoptotic activity and tumour-suppressive function in DLBCL cells (Sewastianik et al. 2016). Taken together, the acetylation and deacetylation of FOXO1 harmoniously alter its function and transcriptional activity during adipocyte differentiation.

\section{Interaction between acetylation and phosphorylation} of FOXO1 in adipocyte differentiation

The interaction of acetylation and phosphorylation in the regulation of FOXO1 were also found in adipocyte differentiation. Matsuzaki et al. have shown that FOXO1 acetylation leads to an increase in AKT-mediated phosphorylation of FOXO1 at S253, thereby further diminishing FOXO1 binding to DNA (Matsuzaki et al. 2005). In addition, Qiang et al. also confirmed that acetylated FOXO is more likely to be translocated to the cytoplasm (Qiang et al. 2010). Moreover, the N-terminal AKT phosphorylation site also regulates the binding of FOXO proteins to $\mathrm{CBP} / \mathrm{P} 300$. Mahmud et al. reported that the addition of growth factor and the phosphorylation of N-terminal AKT phosphorylation motifs interfered with the interaction between CBP/P300 and FOXO3 (Mahmud et al. 2002), which may block the FOXO3 acetylation and directly affect the transcriptional activation mediated by FOXO3 (Van Der Heide et al. 2004). In the nucleus, FOXO1 recognizes and binds to the promoter of target 
genes. When CBP/P300 is recruited into the FOXO1DNA complex, it can result in two consequences. On the one hand, CBP/P300-mediated histone acetylation facilitates the transcription of FOXO1-targeted genes (Yang et al. 2009); on the other hand, the CBP/P300mediated FOXO1 acetylation will then attenuate its DNA-binding affinity (Matsuzaki et al. 2005). Therefore, AKT can effectively phosphorylate the acetylated FOXO1 (Fig. 2). Subsequently, p-FOXO1 interacts with 14-3-3 in the nucleus, which deactivates NLS. Meanwhile, p-FOXO1 interferes with the CBP/P300 recruitment to initiate a series of protein-protein interactions, such as 14-3-3 and exportin/CRM1, which eventually leads to the cytoplasmic retention of FOXO1 (Vogt et al. 2005).

\section{Histone deacetylase: SIRTs}

Sirtuins (SIRTs) participate in the regulation of metabolic pathway by deacetylating proteins (Lavu et al. 2008, Kelly 2010). Till date, seven SIRTs were reported to be identified. Among these SIRTs, SIRT1 plays the most critical role in the regulation of metabolic pathways by deacetylating FOXO1 in the nucleus (Fig. 2) (Schug \& Li 2011, Carafa et al. 2012). SIRT2 and SIRT 3 deacetylate FOXO1 in the cytoplasm and mitochondria, respectively (Daitoku et al. 2011). Oliveira et al. reported that the expression of AMPK and FOXO1 in the murine adipose tissue was increased after treatment with resveratrol, a natural activator of the SIRTs family extracted from traditional Chinese medicine Polygonum cuspidatum (Oliveira Andrade et al. 2014). SIRTs also regulate the expression of adiponectin (Qiang et al. 2007) and TNF- $\alpha$ (Gillum et al. 2011, Lin et al. 2012), as well as take part in the energy balance at the level of hypothalamus (Çakir et al. 2009, Sasaki \& Kitamura 2010). In addition, SIRTs play significant roles in lipogenesis, lipid hydrolysis and fatty acid mobilization during fasting (Picard et al. 2004, Chakrabarti et al. 2011).

SIRT1, a mammalian ortholog of yeast SIR2, is a NADdependent deacetylase that regulates several transcription factors, co-repressors and co-activators. In particular, SIRT1 deacetylates FOXO1 to increase nuclear retention and FOXO1 activity (Qiang et al. 2010). FOXO1 has a conserved LXXLL motif in their C-terminal region for its binding to SIRT1. The disruption of the LXXLL motif of FOXO1 enhances acetylation of FOXO1 and inhibits the transcriptional activity of FOXO1 in liver (Nakae et al. 2006). In addition, SIRT1 interacts with nuclear receptor's co-repressors to inhibit the transcriptional activities of nuclear receptors, such as PPAR (Bai et al. 2008, Lee et al. 2017). Under the stimulation of growth factor,
SIRT1 is mainly distributed in the nuclei and directly binds to FOXO1. Subsequently, it deacetylates FOXO1 and ultimately increases the transcriptional activity of FOXO1. However, with elongation of deacetylation time, degradation caused by ubiquitin proteosome system also occurs and thus reducing its transcriptional activity (Nakae et al. 2006).

SIRT2 inhibits adipocyte differentiation by deacetylating FOXO1 in the cytoplasm. Jing et al. showed that SIRT2 knockdown during clonal expansion of 3T3L1 adipocyte differentiation enhanced the acetylation of FOXO1 and promoted AKT-mediated phosphorylation, which caused subsequent FOXO1 nuclear exclusion. Whereas the overexpression of SIRT2 antagonized the above-mentioned processes (Jing et al. 2007). Moreover, the results of the Oil Red $O$ staining also showed that SIRT2 knockdown cells exhibited a rapid lipid accumulation after 4 days of differentiation (Jing et al. 2007). The mechanisms underlying the decreasing level of SIRT2 in clonal expansion includes increased acetylation of FOXO1 and direct interaction between SIRT2 and FOXO1 in the cytoplasm, which is consistent with the sigmoid expression pattern of FOXO1 during adipocyte differentiation. This interaction enhances the insulinstimulated phosphorylation of FOXO1 and regulates the translocation of FOXO1 (Jing et al. 2007). Meanwhile, SIRT2 also promotes the binding of FOXO1 to PPAR $\gamma$, thereby it inhibits the transcriptional activity of PPAR $\gamma$ (Fei \& Qiang 2009).

\section{FOX01 methylation and O-GIcNAcylation}

Methylation is known as a type of arginine modification that positively or negatively influences protein or RNA activity (Poornima et al. 2016). Protein arginine methyltransferase-1 (PRMT1) mediates FOXO1 methylation at conserved R248 and R250 in the phosphorylation motif of AKT, suggesting that this methylation interferes with the ability of AKT to phosphorylate the S253 FOXO1 (S256 in human FOXO1) during adipocyte differentiation (Yamagata et al. 2008). The knockdown of PRMT1 promoted the decrease of FOXO1 function through its increased nucleus exclusion and protein degradation. PRMT1 knockdown also inhibited the hepatic gluconeogenesis by facilitating the phosphorylation of FOXO1 (Choi et al. 2012). Lv et al. also reported the knockdown of PRMT1-induced glucosestimulated insulin secretion, promoting the methylation and nuclear localization of FOXO1 in INS-1 cells (Lv et al. 2015). However, the effect of PRMT1 on FOXO1 
methylation in 3T3-L1 or other precursor adipocytes has not been reported yet, which needs to be further explored according to the known mechanism.

O-GlcNAcylation means that an O-GlcNAc group is added to the serine/threonine residues of protein and it is a reversible post-translation modification of proteins (Xie et al. 2012). Fardini et al. found that the O-GlcNAcylation of FOXO1 enhanced the transcriptional activity of FOXO1 by promoting nuclear retention whereas inhibited AKT activity through the expression of IGFBP1 (Fardini et al. 2014). O-GlcNAcylation involves O-linked b- $N$-acetyl glucosamine transferase (OGT) and O-linked b- $\mathrm{N}$ acetylglucosaminidase (OGA), which are responsible for the addition and removal of O-GlcNAc, respectively (Xie et al. 2012). Housley et al. identified FOXO1 residues S550, T648, S654 and T317 as GlcNAcylated products by electron transfer dissociation tandem mass spectrometry (ETD-MS/MS). Only the mutation of T317 to alanine could reduce the transcriptional activity of FOXO1 by high glucose, while the mutation of other residues had no such effect (Housley et al. 2008). Later, Fardini et al. identified a new O-GlcNAcylation site T646 on FOXO1, whereas its mutation fails to impact the FOXO1 O-GlcNAcylation and transcriptional activity, suggesting that O-GlcNAcylated residues remain to be explored (Fardini et al. 2015). Housley et al. showed that high glucose upregulated mRNA expression of Pepck and G6pc by increasing GlcNAcylation of FOXO1 in the absence of insulin (Housley et al. 2008). Moreover, Whelan et al. reported that increasing O-GlcNAc in 3T3-L1 adipocytes could reduce the interaction of PI3K with IRS1 and IRS2, as well as the phosphorylation of AKT, suggesting O-GlcNAcylation of FOXO1 is crucial in adipogenesis regulation (Whelan et al. 2010). Similar to methylation, most of the studies on FOXO1 O-GlcNAcylation were limited to the mechanism of glucogenesis on hepatocytes and islet $\beta$ cells under simulated hyperglycemia, but little is known about FOXO1 O-GlcNAcylation in adipocyte differentiation, which should be further researched.

\section{FOX01 and the cell cycle}

FOXO1 is thought to inhibit adipocyte differentiation via cell cycle control. FOXO1, together with PI3K and AKT proteins, was reported to be fundamental signal transduction elements of insulin or IGFs signalling in 3T3L1 adipocytes (Nakae et al. 2003, 2008b, Obsil \& Obsilova 2008). FOXOs can upregulate negative regulators of the G1/S transition of the cell cycle, such as p21, p27 and p130 (Huang \& Tindall 2007a). Scientists have shown that FOXO1 can arrest hepatic stellate cells in G0/G1 phase via p21 and p27 (Adachi et al. 2007). Nakae et al. reported that the downstream proteins of FOXO1 include cell cycle inhibitors, such as p21/p27/pRB, and 3T3-L1 cells were arrested in G0/G1 phase by overexpression of FOXO1 (Nakae et al. 2003). While AKT phosphorylates FOXO1, it also elicits the phosphorylation of p27 at T157 (Tsujimura \& Obata 2000, Liang et al. 2002, Shin et al. 2002). Notably, when p27 was located in the cytoplasm, it did not prevent the progress of the cell cycle but can promote cell migration and movement (Wu et al. 2006). The re-localization of p27 in rodent cells was observed after PI3K/AKT activation (Fujita et al. 2003). Meanwhile, AKT-phosphorylated FOXO1 induces phosphorylation of p21 at T145. Like p27, the phosphorylation of p21 leads to the cytoplasmic localization of p21 (Zhou et al. 2001). In general, FOXO1 regulates adipocyte differentiation through eliciting cell cycle arrest and upregulating the expression of p21 and p27 in a sigmoid activation pattern, which plays an inhibitory role in the early period of adipocyte proliferation and the clonal expansion.

Cyclin-dependent kinase 1 (CDK1) phosphorylates FOXO1 at S249 (Liu et al. 2008, Yuan et al. 2008). Yuan et al. demonstrated that CDK1 did not affect the phosphorylation of S256, but pS249 inhibited the interaction between pS256 and 14-3-3, which led to nuclear retention and activation of FOXO1-dependent transcription (Yuan et al. 2008). Intriguingly, CDK2 phosphorylates FOXO1 at S249 as well, resulting in the cytoplasmic localization and inhibition of FOXO1 (Huang et al. 2006, Huang \& Tindall 2007a). Recently, Kim et al. reported CDK2 could phosphorylate FOXO1 in MIN6 cells and human $\beta$-cells at the S256 residue, a key to FOXO1 shuttling, which may explain why CDK2-mediated phosphorylation of FOXO1 leads to cytoplasmic retention (Kim et al. 2017). More experiments are required to further illustrate the relationship between CDKs and FOXO1.

FOXO1 activates the transcription of $\mathrm{p} 21$ and p27 and simultaneously inhibits the transcriptional activity of cyclins D1 and D2 (Greer \& Brunet 2008). It was reported that FOXO1 mutant (H215R) failed to bind to the FOXOrecognition element (FRE) sequence and was therefore recruited to the promoters of cyclins D1 and D2 to inhibit their transcription activity (Ramaswamy et al. 2002). A conservative FRE, (G/C)(T/A)AA(C/T)AA, was identified by high-affinity DNA-binding studies (Gilley et al. 2003). In fact, functional FRE sites have been recognized in the promoters encoding fatty acid synthetase (FAS) ligands, insulin-like growth factor-binding protein 1 (IGFBP1) and some other proteins (Accili \& Arden 2004, Greer \& 
Brunet 2005). FOXO1 may inhibit its own expression by a crosstalk with other transcriptional regulators or by genes containing FRE-independent FOXO-binding elements in their promoters (Ramaswamy et al. 2002, Schmidt et al. 2002, Huang \& Tindall 2007b). In addition to being involved in cell cycle regulation, cyclin D1 has been demonstrated to inhibit PPAR $\gamma$-mediated lipogenesis through HDACs recruitment (Fu et al. 2005). Altogether, these data suggest that FOXO1 plays a dominant role in cell cycle control of adipocyte differentiation.

\section{FOX01 and lipogenesis}

FOXO1 is also deemed to inhibit adipocyte differentiation through suppressing lipogenesis. The anti-lipogenic effect of FOXO1 seems to be controlled by insulin signals. When the insulin receptor IRS or the insulin target AKT were absent, the activity of FOXO1 was reinforced, resulting in the blocking of adipocyte differentiation (Accili \& Taylor 1991, Miki et al. 2001, Tseng et al. 2004). FOXO1 regulates the expression and transcriptional activity of PPAR $\gamma$ and CCAAT-enhancer-binding proteins (C/EBPs), two pivotal transcription factors in lipogenesis of terminal differentiation (Cristancho \& Lazar 2011). Rapid activation of $\mathrm{C} / \mathrm{EBP} \beta$ and $\mathrm{C} / \mathrm{EBP} \delta$ upregulates the expression of PPAR $\gamma$ at the early stage of differentiation (Farmer 2006). Meanwhile, the mRNA level of PPAR $\gamma$ increases during adipocyte differentiation (Liu et al. 2014). PPAR $\gamma$ modulates the expression of genes encoding enzymes which are involved in glucolipid metabolism and effectors in lipogenesis, such as GLUT-4 (MacDougald \& Lane 1995). Translocation of GLUT-4 from cytoplasm to cell membrane regulates glucose uptake in adipose tissue and skeletal muscle (Jackson et al. 2000, Singh et al. 2011). Activated FOXO1 binds to the PPAR $\gamma$ promoter and inhibits the transcriptional activity of PPAR $\gamma$ by competitively suppressing the formation of functional PPAR $\gamma /$ retinoid X receptor (RXR) complex, thus inhibiting the adipose differentiation (Armoni et al. 2006, Kousteni 2012). Meanwhile, the inhibition of FOXO1 activity in WAT enhances glucose tolerance, insulin sensitivity and energy consumption in both normal and high-fat diet transgenic mice with the deletion of TAD (Nakae et al. 2008a). All of these indicate that FOXO1 plays an important role in lipogenesis.

\section{FOX01 and microRNA}

MicroRNA (miRNA) is a small non-coding RNA with a length of approximately 18-24 nt (Maute et al. 2013). It binds to the 3 '-untranslated region (UTR) of target mRNA to perform mRNA cleavage and translational repression of target genes (Bartel 2004). miRNA is involved in various important cell processes, including early development (Reinhart et al. 2000), fat metabolism (Xu et al. 2003), cell proliferation and cell differentiation (Kawasaki \& Taira 2003). It has been reported that miR-143, miR-375, miR-103 and miR-107 enhanced adipocyte differentiation (Esau et al. 2004, Ling et al. 2011, Trajkovski et al. 2011), whereas miR-27b, let-7 and miR-138 repressed adipogenesis (Karbiener et al. 2009, Sun et al. 2009, Yang et al. 2011). Furthermore, Ahn et al. demonstrated that miR-146b facilitated adipocyte differentiation through downregulation of SIRT1 mRNA level and promotion of FOXO1 acetylation (Ahn et al. 2013, Li et al. 2017). Dong et al. reported that both transcriptional and translational levels of several novel lipogenic genes were upregulated by overexpression of $\mathrm{miR}-15 \mathrm{a} / \mathrm{b}$ in the porcine preadipocytes, which promoted adipocyte differentiation and lipogenesis through suppression of FOXO1 (Dong et al. 2014). Dong et al. also reported that the expression level of miR-15a/b was relatively high during the early stage of adipocyte differentiation and decreased after culture for 4 days, which was consistent with the dynamic change in expression level of FOXO1 as mentioned above.

In recent years, a large number of studies have found and characterized different modification types of RNA base in coding and non-coding RNA, which have been termed as 'epitranscriptomics' (Frye et al. 2016). With the innovative chemical and biochemical techniques, the dynamic RNA modifications have been recognized in the transcriptome, including N1-methyladenosine (m1A), N6-methyladenosine (m6A), inosine (I), pseudouridine $(\Psi)$, 5-methylcytosine (m5C) and 5-hydroxymethylcytosine (hm5C) (Song \& Yi 2017). It has been reported that the RNA modifications on miRNA are mainly m5C and m6A (Li \& Mason 2014). Meanwhile, Xhemalce et al. thought that RNA modifications on miRNA mainly affect the specificity and efficacy of miRNA through methylation and epitranscriptomic changes (Xhemalce et al. 2012). Consequently, we believe that with further studies of RNA modification on certain related miRNA of FOXO1, the corresponding FOXO1 regulation mechanisms will be clarified, and the understanding of the regulation mechanism of FOXO1 in adipocyte differentiation will be further deepened.

\section{Conclusion}

In general, FOXO1 regulates adipocyte differentiation through the control of the cell cycle and lipogenesis in 


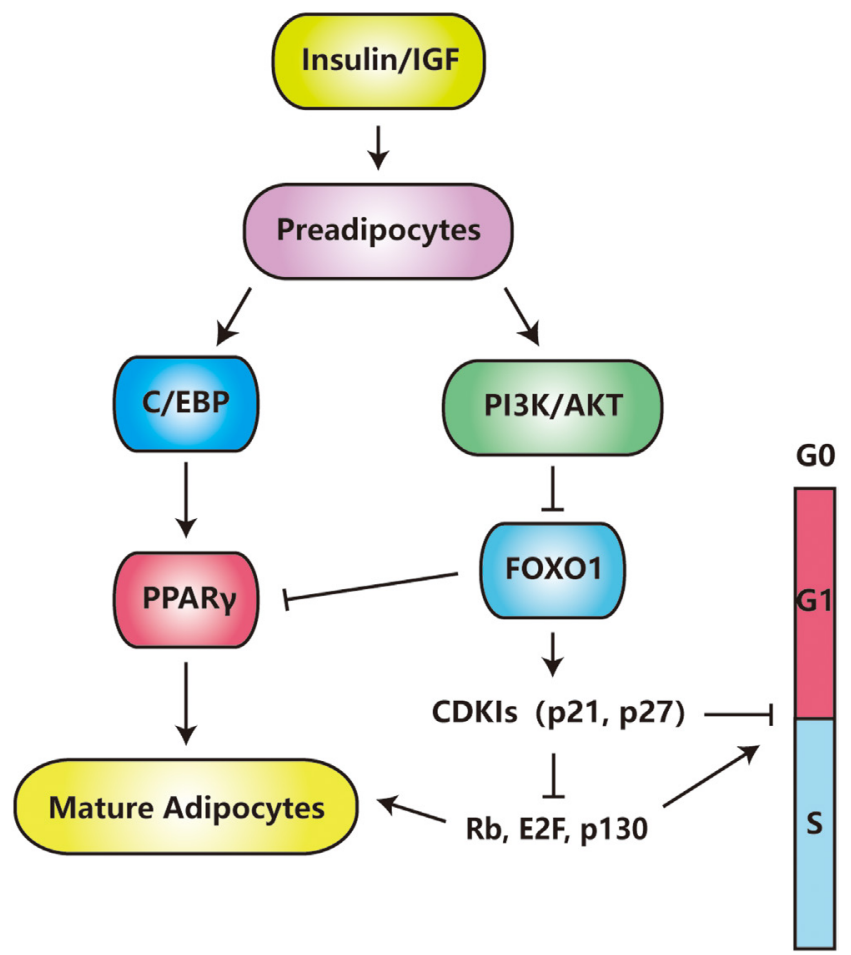

Figure 3

FOXO1 regulates adipocyte differentiation via cell cycle control and adipogenesis. FOXO1 participates in cell cycle regulation through p21 and p27, and takes part in lipogenesis by inhibiting the transcriptional activity of PPAR $\gamma$ to regulate adipocyte differentiation. A full colour version of this figure is available at https://doi.org/10.1530/JME-18-0178.

a periodic dynamic fluctuation manner (Fig. 3). These two events are influenced by the translocation of FOXO1, which determines its activity and has been shown to be associated with its post-translational modifications and interactions with 14-3-3 and SIRTs and so on. Given the poor links between the regulatory mechanisms in which FOXO1 is involved, current studies are almost devoted to distinct parts of FOXO1 regulation during adipocyte differentiation. We summarized the molecular mechanism of FOXO1 transcriptional activity regulation during adipocyte differentiation. FOXO1 acetylation, methylation and O-GlcNAcylation could interact with its phosphorylation and alter the DNA-binding affinity of FOXO1, which further influences the transcription activation by FOXO1. Moreover, acetylation and phosphorylation of FOXO1 synergistically facilitate its nuclear shuttling, whereas methylation and O-GlcNAcylation of FOXO1 interfere with FOXO1 phosphorylation. In view of the mechanism as described above, FOXO1 could elicit cell cycle arrest and upregulates cell cycle inhibitors p21 and p27 in a sigmoid activation pattern in the early period of adipocyte differentiation and the clonal expansion. While during the terminal differentiation, activated FOXO1 binds to the PPAR $\gamma$ promoter and inhibits the transcriptional activity of PPAR $\gamma$ by competitively suppressing the formation of functional PPAR $\gamma / R X R / D N A$ complex, thereby inhibiting lipogenesis and adipocyte differentiation. By providing a more comprehensive overview of the regulatory network and linking separate events of FOXO1 regulation in adipocyte differentiation, our work is expected to provide more FOXO1-related targets, such as miRNA modifications, for further researches.

Declaration of interest

The authors declare that there is no conflict of interest that could be perceived as prejudicing the impartiality of this review.

\section{Funding}

This work was supported by the research grants from the National Natural Scientific Foundation of China (31660323, 81360060, 81070633 and 30860111$)$ and the research projects from the Jiangxi Provincial Department of Science \& Technology (20123BCB22005).

\section{Acknowledgements}

The authors would like to thank Dr Chengqi Yi for the guidance of RNA modification mechanisms, and Cheng Qin and Wentai Shangguan for their help with this manuscript.

\section{References}

Accili D \& Taylor SI 1991 Targeted inactivation of the insulin receptor gene in mouse 3T3-L1 fibroblasts via homologous recombination. PNAS 88 4708-4712. (https://doi.org/10.1073/pnas.88.11.4708)

Accili D \& Arden KC 2004 FoxOs at the crossroads of cellular metabolism, differentiation, and transformation. Cell 117 421-426. (https://doi.org/10.1016/S0092-8674(04)00452-0)

Adachi M, Osawa Y, Uchinami H, Kitamura T, Accili D \& Brenner DA 2007 The forkhead transcription factor FoxO1 regulates proliferation and transdifferentiation of hepatic stellate cells. Gastroenterology 132 1434-1446. (https://doi.org/10.1053/j.gastro.2007.01.033)

Ahn J, Lee H, Jung CH, Jeon TI \& Ha TY 2013 MicroRNA-146b promotes adipogenesis by suppressing the SIRT1-FOXO1 cascade. EMBO Molecular Medicine 5 1602-1612. (https://doi.org/10.1002/ emmm.201302647)

Alessi DR, Caudwell FB, Andjelkovic M, Hemmings BA \& Cohen P 1996 Molecular basis for the substrate specificity of protein kinase B; comparison with MAPKAP kinase-1 and p70 S6 kinase. FEBS Letters 399 333-338. (https://doi.org/10.1016/S0014-5793(96)01370-1).

Armoni M, Harel C, Karni S, Chen H, Bar-Yoseph F, Ver MR, Quon MJ \& Karnieli E 2006 FOXO1 represses peroxisome proliferator-activated receptor-gamma1 and -gamma2 gene promoters in primary adipocytes: a novel paradigm to increase insulin sensitivity. Journal of Biological Chemistry 281 19881-19891. (https://doi.org/10.1074/ jbc.M600320200)

Asada S, Daitoku H, Matsuzaki H, Saito T, Sudo T, Mukai H, Iwashita S, Kako K, Kishi T, Kasuya Y, et al. 2007 Mitogen-activated protein 
kinases, Erk and p38, phosphorylate and regulate FoxO1. Cellular Signalling 19 519-527. (https://doi.org/10.1016/j.cellsig.2006.08.015)

Bai L, Pang WJ, Yang YJ \& Yang GS 2008 Modulation of Sirt1 by resveratrol and nicotinamide alters proliferation and differentiation of pig preadipocytes. Molecular and Cellular Biochemistry 307 129-140. (https://doi.org/10.1007/s11010-007-9592-5)

Bartel DP 2004 MicroRNAs: genomics, biogenesis, mechanism, and function. Cell 116 281-297. (https://doi.org/10.1016/S00928674(04)00045-5).

Battiprolu PK, Hojayev B, Jiang N, Wang ZV, Luo X, Iglewski M, Shelton JM, Gerard RD, Rothermel BA, Gillette TG, et al. 2012 Metabolic stress-induced acrivation of FoxO1 triggers diabetic cardiomyopathy in mice. Journal of Clinical Investigation 122 1109-1118. (https://doi.org/10.1172/JCI60329)

Boström P, Wu J, Jedrychowski MP, Korde A, Ye L, Lo JC, Rasbach KA, Boström EA, Choi JH, Long JZ, et al. 2012 A PGC1- $\alpha$-dependent myokine that drives brown-fat-like development of white fat and thermogenesis. Nature 481 463-468. (https://doi.org/10.1038/ nature10777)

Brent MM, Anand R \& Marmorstein R 2008 Structural basis for DNA recognition by FoxO1 and its regulation by posttranslational modification. Structure 16 1407-1416. (https://doi.org/10.1016/j. str.2008.06.013)

Brownawell AM, Kops GJ, Macara IG \& Burgering BM 2001 Inhibition of nuclear import by protein kinase B (Akt) regulates the subcellular distribution and activity of the forkhead transcription factor AFX. Molecular and Cellular Biology 21 3534-3546. (https://doi. org/10.1128/MСВ.21.10.3534-3546.2001)

Brunet A, Bonni A, Zigmond MJ, Lin MZ, Juo P, Hu LS, Anderson MJ, Arden KC, Blenis J \& Greenberg ME 1999 Akt promotes cell survival by phosphorylating and inhibiting a forkhead transcription factor. Cell 96 857-868. (https://doi.org/10.1016/S0092-8674(00)80595-4)

Brunet A, Kanai F, Stehn J, Xu J, Sarbassova D, Frangioni JV, Dalal SN, Decaprio JA, Greenberg ME \& Yaffe MB 2002 14-3-3 transits to the nucleus and participates in dynamic nucleocytoplasmic transport. Journal of Cell Biology 156 817-828. (https://doi.org/10.1083/ jcb.200112059)

Çakir I, Perello M, Lansari O, Messier NJ, Vaslet CA \& Nillni EA 2009 Hypothalamic Sirt1 regulates food intake in a rodent model system. PLoS One 4. (https://doi.org/10.1371/journal.pone.0008322)

Calnan DR \& Brunet A 2008 The FoxO code. Oncogene 27 2276-2288. (https://doi.org/10.1038/onc.2008.21)

Carafa V, Nebbioso A \& Altucci L 2012 Sirtuins and disease: the road ahead. Frontiers in Pharmacology 3 4. (https://doi.org/10.3389/ fphar.2012.00004)

Chakrabarti P, English T, Karki S, Qiang L, Tao R, Kim J, Luo Z, Farmer SR \& Kandror KV 2011 SIRT1 controls lipolysis in adipocytes via FOXO1-mediated expression of ATGL. Journal of Lipid Research $\mathbf{5 2}$ 1693-1701. (https://doi.org/10.1194/jlr.M014647)

Cheng Z \& White MF 2011 Targeting forkhead box O1 from the concept to metabolic diseases: lessons from mouse models. Antioxidants and Redox Signaling 14 649-661. (https://doi. org/10.1089/ars.2010.3370)

Choi D, Oh KJ, Han HS, Yoon YS, Jung CY, Kim ST \& Koo SH 2012 Protein arginine methyltransferase 1 regulates hepatic glucose production in a FoxO1-dependent manner. Hepatology $\mathbf{5 6}$ 1546-1556. (https://doi.org/10.1002/hep.25809)

Cinti S 2005 The adipose organ. In Prostaglandins, Leukotrienes and Essential Fatty Acids 73 9-15. (https://doi.org/10.1016/j. plefa.2005.04.010)

Clark KL, Halay ED, Lai E \& Burley SK 1993 Co-crystal structure of the HNF-3/fork head DNA-recognition motif resembles histone H5. Nature 364 412-420. (https://doi.org/10.1038/364412a0)

Cornelius P, Macdougald OA \& Lane MD 1994 Regulation of adipocyte development. Annual Review of Nutrition 14 99-129. (https://doi. org/10.1146/annurev.nutr.14.1.99).
Cristancho AG \& Lazar MA 2011 Forming functional fat: a growing understanding of adipocyte differentiation. Nature Reviews Molecular Cell Biology 12 722-734. (https://doi.org/10.1038/nrm3198)

Daitoku H, Sakamaki JI \& Fukamizu A 2011 Regulation of FoxO transcription factors by acetylation and protein-protein interactions. Biochimica et Biophysica Acta 1813 1954-1960. (https://doi. org/10.1016/j.bbamcr.2011.03.001)

Datta SR, Brunet A \& Greenberg ME 1999 Cellular survival: A play in three akts. Genes and Development 13 2905-2927. (https://doi. org/10.1101/gad.13.22.2905)

Dobson M, Ramakrishnan G, Ma S, Kaplun L, Balan V, Fridman R \& Tzivion G 2011 Bimodal regulation of FoxO3 by AKT and 14-3-3. Biochimica et Biophysica Acta 1813 1453-1464. (https://doi. org/10.1016/j.bbamcr.2011.05.001)

Dominy JE \& Puigserver P 2010 Nuclear FoxO1 inflames insulin resistance. ЕMBO Journal 29 4068-4069. (https://doi.org/10.1038/ emboj.2010.305)

Dong P, Mai Y, Zhang Z, Mi L, Wu G, Chu G, Yang G \& Sun S 2014 MiR-15a/b promote adipogenesis in porcine pre-adipocyte via repressing FoxO1. Acta Biochimica et Biophysica Sinica 46 565-571. (https://doi.org/10.1093/abbs/gmu043)

Dowell P, Otto TC, Adi S \& Lane MD 2003 Convergence of peroxisome proliferator-activated receptor gamma and FoxO1 signaling pathways. Journal of Biological Chemistry 278 45485-45491. (https:// doi.org/10.1074/jbc.M309069200)

Esau C, Kang X, Peralta E, Hanson E, Marcusson EG, Ravichandran LV, Sun Y, Koo S, Perera RJ, Jain R, et al. 2004 MicroRNA-143 regulates adipocyte differentiation. Journal of Biological Chemistry 279 52361-52365. (https://doi.org/10.1074/jbc.C400438200)

Evans RM, Barish GD \& Wang YX 2004 PPARs and the complex journey to obesity. Nature Medicine 10 355-361. (https://doi.org/10.1038/ $\mathrm{nm} 1025)$

Fardini Y, Masson E, Boudah O, Ben Jouira R, Cosson C, PierreEugene C, Kuo MS \& Issad T 2014 O-GlcNAcylation of FoxO1 in pancreatic $\beta$ cells promotes Akt inhibition through an IGFBP1mediated autocrine mechanism. FASEB Journal 28 1010-1021. (https://doi.org/10.1096/fj.13-238378)

Fardini Y, Perez-Cervera Y, Camoin L, Pagesy P, Lefebvre T \& Issad T 2015 Regulatory O-GlcNAcylation sites on FoxO1 are yet to be identified. Biochemical and Biophysical Research Communications 462 151-158. (https://doi.org/10.1016/j.bbrc.2015.04.114)

Farmer SR 2006 Transcriptional control of adipocyte formation. Cell Metabolism 4 263-273. (https://doi.org/10.1016/j. cmet.2006.07.001)

Fei W \& Qiang T 2009 SIRT2 suppresses adipocyte differentiation by deacetylating FOXO1 and enhancing FOXO1's repressive interaction with PPAR $\gamma$. Molecular Biology of the Cell 20 801-808. (https://doi. org/10.1091/mbc.E08)

Frye M, Jaffrey SR, Pan T, Rechavi G \& Suzuki T 2016 RNA modifications: what have we learned and where are we headed? Nature Reviews Genetics 17 365-372. (https://doi.org/10.1038/ nrg.2016.47)

Fu M, Rao M, Bouras T, Wang C, Wu K, Zhang X, Li Z, Yao TP \& Pestell RG 2005 Cyclin D1 inhibits peroxisome proliferator-activated receptor $\gamma$-mediated adipogenesis through histone deacetylase recruitment. Journal of Biological Chemistry 280 16934-16941. (https://doi.org/10.1074/jbc.M500403200)

Fujita N, Sato S \& Tsuruo T 2003 Phosphorylation of p27Kip1 at threonine 198 by p90 ribosomal protein S6 kinases promotes its binding to 14-3-3 and cytoplasmic localization. Journal of Biological Chemistry 278 49254-49260. (https://doi.org/10.1074/jbc. M306614200)

Galili N, Davis RJ, Fredericks WJ, Mukhopadhyay S, Rauscher FJ, Emanuel BS, Rovera G \& Barr FG 1993 Fusion of a fork head domain gene to PAX3 in the solid tumour alveolar rhabdomyosarcoma. Nature Genetics 5 230-235. (https://doi.org/10.1038/ng1193-230) 
Gerin I, Bommer GT, Lidell ME, Cederberg A, Enerback S \& McDougald OA 2009 On the role of FOX transcription factors in adipocyte differentiation and insulin-stimulated glucose uptake. Journal of Biological Chemistry 284 10755-10763. (https://doi. org/10.1074/jbc.M809115200)

Gilley J, Coffer PJ \& Ham J 2003 FOXO transcription factors directly activate bim gene expression and promote apoptosis in sympathetic neurons. Journal of Cell Biology 162 613-622. (https://doi. org/10.1083/jcb.200303026)

Gillum MP, Kotas ME, Erion DM, Kursawe R, Chatterjee P, Nead KT, Muise ES, Hsiao JJ, Frederick DW, Yonemitsu S, et al. 2011 SirT1 regulates adipose tissue inflammation. Diabetes $603235-3245$. (https://doi.org/10.2337/db11-0616)

Greer EL \& Brunet A 2005 FOXO transcription factors at the interface between longevity and tumor suppression. Oncogene 24 7410-7425. (https://doi.org/10.1038/sj.onc.1209086)

Greer EL \& Brunet A 2008 FOXO transcription factors in ageing and cancer. Acta Physiologica 192 19-28. (https://doi. org/10.1111/j.1748-1716.2007.01780.x)

Guo S, Rena G, Cichy S, He X, Cohen P \& Unterman T 1999 Phosphorylation of serine 256 by protein kinase B disrupts transactivation by FKHR and mediates effects of insulin on insulinlike growth factor-binding protein-1 promoter activity through a consereved insulin response sequence. Journal of Biological Chemistry 274 17184-17192. (https://doi.org/10.1074/jbc.274.24.17184)

Harms M \& Seale P 2013 Brown and beige fat: development, function and therapeutic potential. Nature Medicine 19 1252-1263. (https:// doi.org/10.1038/nm.3361)

Hermeking H \& Benzinger A 2006 14-3-3 proteins in cell cycle regulation. Seminars in Cancer Biology 16 183-192. (https://doi. org/10.1016/j.semcancer.2006.03.002)

Hotamisligil GS 2006 Inflammation and metabolic disorders. Nature $\mathbf{4 4 4}$ 860-867. (https://doi.org/10.1038/nature05485)

Housley MP, Rodgers JT, Udeshi ND, Kelly TJ, Shabanowitz J, Hunt DF, Puigserver P \& Hart GW 2008 O-GlcNAc regulates FoxO activation in response to glucose. Journal of Biological Chemistry $\mathbf{2 8 3}$ 16283-16292. (https://doi.org/10.1074/jbc.M802240200)

Hribal ML, Nakae J, Kitamura T, Shutter JR \& Accili D 2003 Regulation of insulin-like growth factor-dependent myoblast differentiation by Foxo forkhead transcription factors. Journal of Cell Biology 162 535-541. (https://doi.org/10.1083/jcb.200212107)

Huang H, Regan KM, Lou Z, Chen J \& Tindall DJ 2006 CDK2-dependent phosphorylation of FOXO1 as an apoptotic response to DNA damage. Science 314 294-297. (https://doi.org/10.1126/ science.1130512)

Huang $\mathrm{H} \&$ Tindall DJ 2007a CDK2 and FOXO1: a fork in the road for cell fate decisions. Cell Cycle 6 902-906. (https://doi.org/10.4161/ cc.6.8.4122)

Huang H \& Tindall DJ 2007b Dynamic FoxO transcription factors. Journal of Cell Science 120 2479-2487. (https://doi.org/10.1242/ jcs.001222)

Jackson S, Bagstaff SM, Lynn S, Yeaman SJ, Turnbull DM \& Walker M 2000 Decreased insulin responsiveness of glucose uptake in cultured human skeletal muscle cells: from insulin-resistant nondiabetic relatives of type 2 diabetic families. Diabetes 49 1169-1177. (https:// doi.org/10.2337/diabetes.49.7.1169)

Jin C, Marsden I, Chen X \& Liao X 1998 Sequence specific collective motions in a winged helix DNA binding domain detected by $15 \mathrm{~N}$ relaxation NMR. Biochemistry 37 6179-6187. (https://doi. org/10.1021/bi980031v)

Jing E, Gesta S \& Kahn CR 2007 SIRT2 regulates adipocyte differentiation through FoxO1 acetylation/deacetylation. Cell Metabolism 6 105-114. (https://doi.org/10.1016/j.cmet.2007.07.003)

Kaestner KH, Knöchel W, Martínez DE 2000 Unified nomenclature for the winged helix/forkhead transcription factors. Genes and Development 14 142-146. (https://doi.org/10.1101/gad.14.2.142)
Karbiener M, Fischer C, Nowitsch S, Opriessnig P, Papak C, Ailhaud G, Dani C, Amri EZ \& Scheideler M 2009 MicroRNA miR-27b impairs human adipocyte differentiation and targets PPAR $\gamma$. Biochemical and Biophysical Research Communications 390 247-251. (https://doi. org/10.1016/j.bbrc.2009.09.098)

Kawasaki H \& Taira K 2003 Hes1 is a target of microRNA-23 during retinoic-acid-induced neuronal differentiation of NT2 cells. Nature 423 838-842. (https://doi.org/10.1038/nature01730)

Kelly GS 2010 A review of the sirtuin system, its clinical implications, and the potential role of dietary activators like resveratrol: part 2 . Alternative Medicine Review 15 313-328.

Kim H \& Sakamoto K 2012 (-) Epigallocatechin gallate suppresses adipocyte differentiation through the MEK/ERK and PI3K/Akt pathways. Cell Biology International 36 147-153. (https://doi. org/10.1042/CBI20110047)

Kim H, Hiraishi A, Tsuchiya K \& Sakamoto K 2010 (-) Epigallocatechin gallate suppresses the differentiation of 3T3-L1 preadipocytes through transcription factors FoxO1 and SREBP1c. Cytotechnology 62 245-255. (https://doi.org/10.1007/s10616-010-9285-x)

Kim SY, Lee JH, Merrins MJ, Gavrilova O, Bisteau X, Kaldis P, Satin LS \& Rane SG 2017 Loss of cyclin-dependent kinase 2 in the pancreas links primary $\beta$-cell dysfunction to progressive depletion of $\beta$-cell mass and diabetes. Journal of Biological Chemistry 292 3841-3853. (https://doi.org/10.1074/jbc.M116.754077)

Kohn AD, Summers SA, Birnbaum MJ \& Roth RA 1996 Expression of a constitutively active Akt Ser/Thr kinase in 3T3-L1 adipocytes stimulates glucose uptake and glucose transporter 4 translocation. Journal of Biological Chemistry 271 31372-31378. (https://doi. org/10.1074/jbc.271.49.31372)

Kousteni S 2012 FoxO1, the transcriptional chief of staff of energy metabolism. Bone 50 437-443. (https://doi.org/10.1016/j. bone.2011.06.034)

Lai E, Clark KL, Burley SK \& Darnell JE 1993 Hepatocyte nuclear factor 3/fork head or 'winged helix' proteins: a family of transcription factors of diverse biologic function. PNAS 90 10421-10423. (https:// doi.org/10.1073/pnas.90.22.10421)

Lavu S, Boss O, Elliott PJ \& Lambert PD 2008 Sirtuins - novel therapeutic targets to treat age-associated diseases. Nature Reviews Drug Discovery 7 841-853. (https://doi.org/10.1038/nrd2665)

Lawlor MA \& Alessi DR 2001 PKB/Akt: a key mediator of cell proliferation, survival and insulin responses? Journal of Cell Science 114 2903-2910. (https://doi.org/10.1042/bst0290001)

Lee JH, Jung HA, Kang MJ, Choi JS \& Kim GD 2017 Fucosterol, isolated from Ecklonia stolonifera, inhibits adipogenesis through modulation of FoxO1 pathway in 3T3-L1 adipocytes. Journal of Pharmacy and Pharmacology 69 325-333. (https://doi.org/10.1111/jphp.12684)

Li S \& Mason CE 2014 The pivotal regulatory landscape of RNA modifications. Annual Review of Genomics and Human Genetics $\mathbf{1 5}$ 127-150. (https://doi.org/10.1146/annurev-genom-090413-025405)

Li Y, Ma Z, Jiang S, Hu W, Li T, Di S, Wang D \& Yang Y 2017 A global perspective on FOXO1 in lipid metabolism and lipid-related diseases. Progress in Lipid Research 66 42-49. (https://doi.org/10.1016/j. plipres.2017.04.002)

Liang J, Zubovitz J, Petrocelli T, Kotchetkov R, Connor MK, Han K, Lee JH, Ciarallo S, Catzavelos C, Beniston R, et al. 2002 PKB/Akt phosphorylates p27, impairs nuclear import of p27 and opposes p27mediated G1 arrest. Nature Medicine 8 1153-1160. (https://doi. org/10.1038/nm761)

Lin QQ, Yan CF, Lin R, Zhang JY, Wang WR, Yang LN \& Zhang KF 2012 SIRT1 regulates TNF-alpha-induced expression of CD40 in 3T3-L1 adipocytes via NF-kappaB pathway. Cytokine 60 447-455. (https:// doi.org/10.1016/j.cyto.2012.05.025)

Ling HY, Wen GB, Feng SD, Tuo QH, Ou HS, Yao CH, Zhu BY, Gao ZP, Zhang L \& Liao DF 2011 MicroRNA-375 promotes 3T3-L1 adipocyte differentiation through modulation of extracellular signal-regulated kinase signalling. Clinical and Experimental Pharmacology and 
Physiology 38 239-246. (https://doi. org/10.1111/j.1440-1681.2011.05493.x)

Liu P, Kao TP \& Huang H 2008 CDK1 promotes cell proliferation and survival via phosphorylation and inhibition of FOXO1 transcription factor. Oncogene 27 4733-4744. (https://doi.org/10.1038/ onc.2008.104)

Liu X, Liu G, Tan X, Zhao H, Cheng H, Wan F, Wu N \& Song E 2014 Gene expression profiling of SIRT1, FoxO1, and PPAR $\gamma$ in backfat tissues and subcutaneous adipocytes of Lilu bulls. Meat Science $\mathbf{9 6}$ 704-711. (https://doi.org/10.1016/j.meatsci.2013.09.019)

Liu L, Zheng LD, Zou P, Brooke J, Smith C, Long YC, Almeida FA, Liu D \& Cheng Z 2016 FoxO1 antagonist suppresses autophagy and lipid droplet growth in adipocytes. Cell Cycle 15 2033-2041. (https://doi. org/10.1080/15384101.2016.1192732)

Lu Y, Chen J, Xian T, Zhou Y, Yuan W, Wang M, Gan Y, Wang K, Xiong S, Ma C, et al. 2018 Epigallocatechin-3-gallate suppresses differentiation of adipocytes via regulating the phosphorylation of FOXO1 mediated by PI3K-AKT signaling in 3T3-L1 cells. Oncotarget 9 7411-7423. (https://doi.org/10.18632/oncotarget.23590)

Lv L, Chen H, Sun J, Lu D, Chen C \& Liu D 2015 PRMT1 promotes glucose toxicity-induced $\beta$ cell dysfunction by regulating the nucleocytoplasmic trafficking of PDX-1 in a FOXO1-dependent manner in INS-1 cells. Endocrine 49 669-682. (https://doi.org/10.1007/s12020015-0543-8)

MacDougald OA \& Lane MD 1995 Transcriptional regulation of gene expression during adipocyte differentiation. Annual Review of Biochemistry 64 345-373. (https://doi.org/10.1146/annurev. bi.64.070195.002021)

Mahmud DL, G-Amlak M, Deb DK, Platanias LC, Uddin S \& Wickrema A 2002 Phosphorylation of forkhead transcription factors by erythropoietin and stem cell factor prevents acetylation and their interaction with coactivator $\mathrm{p} 300$ in erythroid progenitor cells. Oncogene 21 1556-1562. (https://doi.org/10.1038/sj.onc.1205230)

Marsden I, Chen Y, Jin C \& Liao X 1997 Evidence that the DNA binding specificity of winged helix proteins is mediated by a structural change in the amino acid sequence adjacent to the principal DNA binding helix. Biochemistry 36 13248-13255. (https://doi. org $/ 10.1021 /$ bi971514m)

Marsden I, Jin C \& Liao X 1998 Structural changes in the region directly adjacent to the DNA-binding helix highlight a possible mechanism to explain the observed changes in the sequence-specific binding of winged helix proteins. Journal of Molecular Biology 278 293-299. (https://doi.org/10.1006/jmbi.1998.1703)

Matsumoto M, Pocai A, Rossetti L, Depinho RA \& Accili D 2007 Impaired regulation of hepatic glucose production in mice lacking the forkhead transcription factor FoxO1 in liver. Cell Metabolism 6 208-216. (https://doi.org/10.1016/j.cmet.2007.08.006)

Matsuzaki H, Daitoku H, Hatta M, Aoyama H, Yoshimochi K \& Fukamizu A 2005 Acetylation of FoxO1 alters its DNA-binding ability and sensitivity to phosphorylation. PNAS 102 11278-11283. (https:// doi.org/10.1073/pnas.0502738102)

Maute RL, Schneider C, Sumazin P, Holmes A, Califano A, Basso K \& DallaFavera R 2013 tRNA-derived microRNA modulates proliferation and the DNA damage response and is down-regulated in B cell lymphoma. PNAS 110 1404-1409. (https://doi.org/10.1073/pnas.1206761110)

Miki H, Yamauchi T, Suzuki R, Komeda K, Tsuchida A, Kubota N, Terauchi Y, Kamon J, Kaburagi Y, Matsui J, et al. 2001 Essential role of insulin receptor Substrate 1 (IRS-1) and IRS-2 in adipocyte differentiation. Molecular and Cellular Biology 21 2521-2532. (https:// doi.org/10.1128/MCB.21.7.2521-2532.2001)

Munekata K \& Sakamoto K 2009 Forkhead transcription factor FoxO1 is essential for adipocyte differentiation. In Vitro Cellular and Developmental Biology Animal 45 642-651. (https://doi.org/10.1007/ s11626-009-9230-5)

Nagashima T, Shigematsu N, Maruki R, Urano Y, Tanaka H, Shimaya A, Shimokawa T \& Shibasaki M 2010 Discovery of novel forkhead box
O1 inhibitors for treating type 2 diabetes: improvement of fasting glycemia in diabetic db/db mice. Molecular Pharmacology 78 961-970. (https://doi.org/10.1124/mol.110.065714)

Nakae J, Park BC \& Accili D 1999 Insulin stimulates phosphorylation of the forkhead transcription factor FKHR on serine 253 through a wortmannin-sensitive pathway. Journal of Biological Chemistry $\mathbf{2 7 4}$ 15982-15985. (https://doi.org/10.1074/jbc.274.23.15982)

Nakae J, Barr V \& Accili D 2000 Differential regulation of gene expression by insulin and IGF-1 receptors correlates with phosphorylation of a single amino acid residue in the forkhead transcription factor FKHR. EMBO Journal 19 989-996. (https://doi. org/10.1093/emboj/19.5.989)

Nakae J, Kitamura T, Silver DL \& Accili D 2001 The forkhead transcription factor FoxO1 (Fkhr) confers insulin sensitivity onto glucose-6- phosphatase expression. Journal Clinic in Vest 1081359-1081367. (https://doi.org/10.1172/JCI12876)

Nakae J, Biggs WH, Kitamura T, Cavenee WK, Wright CVE, Arden KC \& Accili D 2002 Regulation of insulin action and pancreatic beta-cell function by mutated alleles of the gene encoding forkhead transcription factor FoxO1. Nature Genetics 32 245-253. (https://doi. org/10.1038/ng890)

Nakae J, Kitamura T, Kitamura Y, Biggs WH, Arden KC \& Accili D 2003 The forkhead transcription factor FoxO1 regulates adipocyte differentiation. Developmental Cell 4 119-129. (https://doi. org/10.1016/S1534-5807(02)00401-X).

Nakae J, Cao Y, Daitoku H, Fukamizu A, Ogawa W, Yano Y \& Hayashi Y 2006 The LXXLL motif of murine forkhead transcription factor FoxO1 mediates Sirt1-dependent transcriptional activity. Journal of Clinical Investigation 116 2473-2483. (https://doi.org/10.1172/ JCI25518)

Nakae J, Cao Y, Oki M, Orba Y, Sawa H, Kiyonari H, Iskandar K, Suga K, Lombes M \& Hayashi Y 2008a Forkhead transcription factor FoxO1 in adipose tissue regulates energy storage and expenditure. Diabetes 57 563-576. (https://doi.org/10.2337/db07-0698)

Nakae J, Oki M \& Cao Y 2008b The FoxO transcription factors and metabolic regulation. FEBS Letters 582 54-67. (https://doi. org/10.1016/j.febslet.2007.11.025)

Nakae J, Cao Y, Hakuno F, Takemori H, Kawano Y, Sekioka R, Abe T, Kiyonari H, Tanaka T, Sakai J, et al. 2012 Novel repressor regulates insulin sensitivity through interaction with FoxO1. EMBO Journal 31 2275-2295. (https://doi.org/10.1038/emboj.2012.97)

Obsil T \& Obsilova V 2008 Structure/function relationships underlying regulation of FOXO transcription factors. Oncogene 27 2263-2275. (https://doi.org/10.1038/onc.2008.20)

Obsil T \& Obsilova V 2011 Structural basis for DNA recognition by FOXO proteins. Biochimica et Biophysica Acta 1813 1946-1953. (https://doi.org/10.1016/j.bbamcr.2010.11.025)

Obsilova V, Vecer J, Herman P, Pabianova A, Sulc M, Teisinger J, Boura E \& Obsil T 2005 14-3-3 protein interacts with nuclear localization sequence of forkhead transcription factor FoxO4. Biochemistry $\mathbf{4 4}$ 11608-11617. (https://doi.org/10.1021/bi050618r)

Ogg S, Paradis S, Gottlieb S, Patterson GI, Lee L, Tissenbaum HA \& Ruvkun G 1997 The Fork head transcription factor DAF-16 transduces insulin-like metabolic and longevity signals in C. elegans. Nature 389 994-999. (https://doi.org/10.1038/40194)

Oliveira Andrade JM, Paraíso AF, Garcia ZM, Ferreira AVM, Sinisterra RDM, Sousa FB, Guimarães ALS, De Paula AMB, Campagnole-Santos MJ, Dos Santos RA, et al. 2014 Cross talk between angiotensin-(1-7)/Mas axis and sirtuins in adipose tissue and metabolism of high-fat feed mice. Peptides 55 158-165. (https:// doi.org/10.1016/j.peptides.2014.03.006)

Ortega-Molina A, Efeyan A, Lopez-Guadamillas E, Muñoz-Martin M, Gómez-López G, Cañamero M, Mulero F, Pastor J, Martinez S, Romanos E, et al. 2012 Pten positively regulates brown adipose function, energy expenditure, and longevity. Cell Metabolism 15 382-394. (https://doi.org/10.1016/j.cmet.2012.02.001) 
Pan CW, Jin X, Zhao Y, Pan Y, Yang J, Karnes RJ, Zhang J, Wang L \& Huang H 2017 AKT-phosphorylated FOXO1 suppresses ERK activation and chemoresistance by disrupting IQGAP1-MAPK interaction. EMBO Journal 36 995-1010. (https://doi.org/10.15252/ embj.201695534)

Picard F, Kurtev M, Chung N, Topark-Ngarm A, Senawong T, De Oliveira RM, Leid M, McBurney MW \& Guarente L 2004 Sirt1 promotes fat mobilization in white adipocytes by repressing PPAR- $\gamma$. Nature 429 771-776. (https://doi.org/10.1038/nature02583)

Poornima G, Shah S, Vignesh V, Parker R \& Rajyaguru PI 2016 Arginine methylation promotes translation repression activity of eIF4Gbinding protein, Scd6. Nucleic Acids Research 44 9358-9368. (https:// doi.org/10.1093/nar/gkw762)

Qiang L, Wang H \& Farmer SR 2007 Adiponectin secretion is regulated by SIRT1 and the endoplasmic reticulum oxidoreductase Ero1-L alpha . Molecular and Cellular Biology 27 4698-4707. (https://doi. org/10.1128/MCB.02279-06)

Qiang L, Banks AS \& Accili D 2010 Uncoupling of acetylation from phosphorylation regulates FoxO1 function independent of its subcellular localization. Journal of Biological Chemistry $\mathbf{2 8 5}$ 27396-27401. (https://doi.org/10.1074/jbc.M110.140228)

Qiang L, Wang L, Kon N, Zhao W, Lee S, Zhang Y, Rosenbaum M, Zhao Y, Gu W, Farmer SR, et al. 2012 Brown remodeling of white adipose tissue by SirT1-dependent deacetylation of PPAR $\gamma$. Cell 150 620-632. (https://doi.org/10.1016/j.cell.2012.06.027)

Ramaswamy S, Nakamura N, Sansal I, Bergeron L \& Sellers WR 2002 A novel mechanism of gene regulation and tumor suppression by the transcription factor FKHR. Cancer Cell 2 81-91. (https://doi. org/10.1016/S1535-6108(02)00086-7).

Reinhart BJ, Slack FJ, Basson M, Pasquienelll AE, Bettlnger JC, Rougvle AE, Horvitz HR \& Ruvkun G 2000 The 21-nucleotide let-7 RNA regulates developmental timing in Caenorhabditis elegans. Nature 403 901-906. (https://doi.org/10.1038/35002607)

Rena G, Prescott AR, Guo S, Cohen P \& Unterman TG 2001 Roles of the forkhead in rhabdomyosarcoma (FKHR) phosphorylation sites in regulating 14-3-3 binding, transactivation and nuclear targetting. Biochemical Journal 354 605-612 [doi:10.1042/bj3540605].

Sakaue H, Ogawa W, Matsumoto M, Kuroda S, Takata M, Sugimoto T, Spiegelman BM \& Kasuga M 1998 Posttranscriptional control of adipocyte differentiation through activation of phosphoinositide 3-kinase. Journal of Biological Chemistry 273 28945-28952. (https:// doi.org/10.1074/jbc.273.44.28945)

Sasaki T \& Kitamura T 2010 Roles of FoxO1 and Sirt1 in the central regulation of food intake. Endocrine Journal 57 939-946. (https://doi. org/10.1507/endocrj.K10E-320)

Schmidt M, Fernandez de Mattos S, van der Horst A, Klompmaker R, Kops GJPL, Lam EW-F, Burgering BMT \& Medema RH 2002 Cell cycle inhibition by FoxO forkhead transcription factors involves downregulation of cyclin D. Molecular and Cellular Biology 22 7842-7852. (https://doi.org/10.1128/MCB.22.22.7842)

Schug TT \& Li X 2011 Sirtuin 1 in lipid metabolism and obesity. Annals of Medicine 43 198-211. (https://doi.org/10.3109/07853890.2010.547 211)

Sewastianik T, Szydlowski M, Jablonska E, Bialopiotrowicz E, Kiliszek P, Gorniak P, Polak A, Prochorec-Sobieszek M, Szumera-Cieckiewicz A, Kaminski TS, et al. 2016 FOXO1 is a TXN-and p300-dependent sensor and effector of oxidative stress in diffuse large B-cell lymphomas characterized by increased oxidative metabolism. Oncogene 35 5989-6000. (https://doi.org/10.1038/onc.2016.126)

Shamina M \& Rangwala MAL 2000 Transcriptional control of adipogenesis. Annual Review of Nutrition 20 535-559. (https://doi. org/10.1146/annurev.micro.56.012302.161103)

Shin I, Yakes FM, Rojo F, Shin NY, Bakin AV, Baselga J \& Arteaga CL $2002 \mathrm{PKB} /$ Akt mediates cell-cycle progression by phosphorylation of p27Kip1at threonine 157 and modulation of its cellular localization. Nature Medicine 8 1145-1152. (https://doi.org/10.1038/nm759)
Silhan J, Vacha P, Strnadova P, Vecer J, Herman P, Sulc M, Teisinger J, Obsilova V \& Obsil T 2009 14-3-3 protein masks the DNA binding interface of forkhead transcription factor FOXO4. Journal of Biological Chemistry 284 19349-19360. (https://doi.org/10.1074/jbc. M109.002725)

Singh BN, Shankar S \& Srivastava RK 2011 Green tea catechin, epigallocatechin-3-gallate (EGCG): mechanisms, perspectives and clinical applications. Biochemical Pharmacology 82 1807-1821. (https://doi.org/10.1016/j.bcp.2011.07.093)

Song J \& Yi C 2017 Chemical modifications to RNA: a new layer of gene expression regulation. ACS Chemical Biology 12 316-325. (https://doi. org/10.1021/acschembio.6b00960)

Song S, Attia RR, Connaughton S, Niesen MI, Ness GC, Elam MB, Hori RT, Cook GA \& Park EA 2010 Peroxisome proliferator activated receptor $\alpha(\mathrm{PPAR} \alpha)$ and PPAR gamma coactivator (PGC-1 $\alpha)$ induce carnitine palmitoyltransferase IA (CPT-1A) via independent gene elements. Molecular and Cellular Endocrinology 325 54-63. (https:// doi.org/10.1016/j.mce.2010.05.019)

Song HM, Song JL, Li DF, Hua KY, Zhao BK \& Fang L 2015 Inhibition of FOXO1 by small interfering RNA enhances proliferation and inhibits apoptosis of papillary thyroid carcinoma cells via Akt/FOXO1/Bim pathway. OncoTargets and Therapy 8 3565-3573. (https://doi. org/10.2147/OTT.S95395)

Sun T, Fu M, Bookout AL, Kliewer SA \& Mangelsdorf DJ 2009 MicroRNA let -7 regulates 3T3-L1 adipogenesis. Molecular Endocrinology 23 925-931. (https://doi.org/10.1210/me.2008-0298)

Tang ED, Nuñez G, Barr FG \& Guan KL 1999 Negative regulation of the forkhead transcription factor FKHR by Akt. Journal of Biological Chemistry 274 16741-16746. (https://doi.org/10.1074/ jbc.274.24.16741)

Tang QQ, Otto TC \& Lane MD 2003 Mitotic clonal expansion: a synchronous process required for adipogenesis. PNAS 100 44-49. (https://doi.org/10.1073/pnas.0137044100)

Trajkovski M, Hausser J, Soutschek J, Bhat B, Akin A, Zavolan M, Heim MH \& Stoffel M 2011 MicroRNAs 103 and 107 regulate insulin sensitivity. Nature 474 649-653. (https://doi.org/10.1038/ nature10112)

Tseng YH, Kriauciunas KM, Kokkotou E \& Kahn CR 2004 Differential roles of insulin receptor substrates in brown adipocyte differentiation. Molecular and Cellular Biology 24 1918-1929. (https:// doi.org/10.1128/MCB.24.5.1918-1929.2004)

Tsujimura K \& Obata Y 2000 AFX-like forkhead transcription factors mediate cell-cycle regulation by Ras and PKB. Nature 404 782-787.

Tzivion G, Dobson M \& Ramakrishnan G 2011 FoxO transcription factors; regulation by AKT and 14-3-3 proteins. Biochimica et Biophysica Acta 1813 1938-1945. (https://doi.org/10.1016/j. bbamcr.2011.06.002)

Van Der Heide LP, Hoekman MFM \& Smidt MP 2004 The ins and outs of FoxO shuttling: mechanisms of FoxO translocation and transcriptional regulation. Biochemical Journal 380 297-309. (https:// doi.org/10.1042/BJ20040167)

Vanhaesebroeck B \& Waterfield MD 1999 Signaling by distinct classes of phosphoinositide 3-kinases. Experimental Cell Research 253 239-254. (https://doi.org/10.1006/excr.1999.4701)

Vanhaesebroeck B \& Alessi DR 2000 The PI3K-PDK1 connection: more than just a road to PKB. Biochemical Journal 346 561-576. (https:// doi.org/10.1042/0264-6021:3460561)

Vogt PK, Jiang H \& Aoki M 2005 Triple layer control: phosphorylation, acetylation and ubiquitination of FOXO proteins. Cell Cycle $\mathbf{4}$ 908-913. (https://doi.org/10.4161/cc.4.7.1796)

Wang Y, Zhou Y \& Graves DT 2014 FOXO transcription factors: their clinical significance and regulation. BioMed Research International 2014 925350. (https://doi.org/10.1155/2014/925350)

Whelan SA, Dias WB, Thiruneelakantapillai L, Daniel Lane MD \& Hart GW 2010 Regulation of insulin receptor substrate 1 (IRS-1)/AKT kinase-mediated insulin signaling by $\mathrm{O}$-linked $\beta$-N-acetylglucosamine https://jme.bioscientifica.com

https://doi.org/10.1530/JME-18-0178 (c) 2019 Society for Endocrinology Published by Bioscientifica Ltd. Printed in Great Britain 
in 3T3-L1 adipocytes. Journal of Biological Chemistry 285 5204-5211. (https://doi.org/10.1074/jbc.M109.077818)

Wu FY, Wang SE, Sanders ME, Shin I, Rojo F, Baselga J \& Arteaga CL 2006 Reduction of cytosolic p27Kip1 inhibits cancer cell motility, survival, and tumorigenicity. Cancer Research 66 2162-2172. (https:// doi.org/10.1158/0008-5472.CAN-05-3304)

Wu J, Boström P, Sparks LM, Ye L, Choi JH, Giang AH, Khandekar M, Virtanen KA, Nuutila P, Schaart G, et al. 2012 Beige adipocytes are a distinct type of thermogenic fat cell in mouse and human. Cell $\mathbf{1 5 0}$ 366-376. (https://doi.org/10.1016/j.cell.2012.05.016)

Wu M, Liu D, Zeng R, Xian T, Lu Y, Zeng G, Sun Z, Huang B \& Huang Q 2017 Epigallocatechin-3-gallate inhibits adipogenesis through downregulation of PPAR $\gamma$ and FAS expression mediated by PI3K-AKT signaling in 3T3-L1 cells. European Journal of Pharmacology 795 134-142. (https://doi.org/10.1016/j.ejphar.2016.12.006)

Xhemalce B, Robson SC \& Kouzarides T 2012 Human RNA methyltransferase BCDIN3D regulates microRNA processing. Cell 151 278-288. (https://doi.org/10.1016/i.cell.2012.08.041)

Xie Q, Chen J \& Yuan Z 2012 Post-translational regulation of FOXO. Acta Biochimica et Biophysica Sinica 44 897-901. (https://doi. org/10.1093/abbs/gms067)

Xu P, Vernooy SY, Guo M \& Hay BA 2003 The Drosophila microRNA mir-14 suppresses cell death and is required for normal fat metabolism. Current Biology 13 790-795. (https://doi.org/10.1016/ S0960-9822(03)00250-1).

Yaffe MB 2002 How do 14-3-3 proteins work? - Gatekeeper phosphorylation and the molecular anvil hypothesis. FEBS Letters 513 53-57. (https://doi.org/10.1016/S0014-5793(01)03288-4).

Yamagata K, Daitoku H, Takahashi Y, Namiki K, Hisatake K, Kako K, Mukai H, Kasuya Y \& Fukamizu A 2008 Arginine methylation of FOXO transcription factors inhibits their phosphorylation by Akt. Molecular Cell 32 221-231. (https://doi.org/10.1016/j. molcel.2008.09.013)

Yan L, Lavin VA, Moser LR, Cui Q, Kanies C \& Yang E 2008 PP2A regulates the pro-apoptotic activity of FOXO1. Journal of Biological Chemistry 283 7411-7420. (https://doi.org/10.1074/jbc.M708083200)
Yang XJ \& Seto E 2008 Lysine acetylation: codified crosstalk with other posttranslational modifications. Molecular Cell 31 449-461. (https:// doi.org/10.1016/j.molcel.2008.07.002)

Yang Y, Zhao Y, Liao W, Yang J, Wu L, Zheng Z, Yu Y, Zhou W, Li L, Feng J, et al. 2009 Acetylation of FoxO1 activates Bim expression to induce apoptosis in response to histone deacetylase inhibitor depsipeptide treatment. Neoplasia 11 313-324. (https://doi. org/10.1593/neo.81358)

Yang Z, Bian C, Zhou H, Huang S, Wang S, Liao L \& Zhao RC 2011 MicroRNA hsa-miR-138 inhibits adipogenic differentiation of human adipose tissue-derived mesenchymal stem cells through adenovirus EID-1. Stem Cells and Development 20 259-267. (https://doi. org/10.1089/scd.2010.0072)

Yuan Z, Becker EBE, Merlo P, Yamada T, DiBacco S, Konishi Y, Schaefer EM \& Bonni A 2008 Activation of FOXO1 by Cdk1 in cycling cells and postmitotic neurons. Science 319 1665-1668. (https://doi.org/10.1126/science.1152337)

Zhang X, Gan L, Pan H, Guo S, He X, Olson ST, Mesecar A, Adam S \& Untermant TG 2002 Phosphorylation of serine 256 suppresses transactivation by FKHR (FOXO1) by multiple mechanisms: direct and indirect effects on nuclear/cytoplasmic shuttling and DNA binding. Journal of Biological Chemistry 277 45276-45284. (https:// doi.org/10.1074/jbc.M208063200)

Zhao X, Gan L, Pan H, Kan D, Majeski M, Adam SA \& Unterman TG 2004 Multiple elements regulate nuclear/cytoplasmic shuttling of FOXO1: characterization of phosphorylation- and 14-3-3-dependent and -independent mechanisms. Biochemical Journal 378 839-849. (https://doi.org/10.1042/BJ20031450)

Zhou BP, Liao Y, Xia W, Spohn B, Lee MH \& Hung MC 2001 Cytoplasmic localization of p21 CIP1/WAF1 by Akt-induced phosphorylation in HER-2/neu-overexpressing cells. Nature Cell Biology 3 245-252. (https://doi.org/10.1038/35060032)

Zou P, Liu L, Zheng L, Liu L, Stoneman RE, Cho A, Emery A, Gilbert ER \& Cheng Z 2014 Targeting FoxO1 with AS1842856 suppresses adipogenesis. Cell Cycle 13 3759-3767. (https://doi.org/10.4161/1538 4101.2014.965977)

Received in final form 10 January 2019

Accepted 5 February 2019

Accepted Preprint published online 5 February 2019 (c) 2019 Society for Endocrinology Published by Bioscientifica Ltd. Printed in Great Britain 